\section{Segmentation Methods for Micro CT Images: A Comparative Study Using Human Bone Samples}

Karla Rovaris ${ }^{1}$, Polyane Mazucatto Queiroz ${ }^{1}$, Karla de Faria Vasconcelos ${ }^{1}$, Lívia dos Santos Corpas², Bernardo Mattos da Silveira ${ }^{3}$, Deborah Queiroz Freitas ${ }^{1}$

\author{
'Department of Oral Diagnosis, \\ Division of Oral Radiology, \\ Piracicaba Dental School, UNICAMP \\ - Universidade Estadual de \\ Campinas, Piracicaba, SP, Brazil \\ ${ }^{2}$ Independent researcher, ORPI \\ -Oral Rehabilitation, Physiology \\ and Imaging, Leuven, Belgium. \\ ${ }^{3}$ Department of Implant Dentistry, \\ ILAPEO - Latin American \\ Institute of Research and Dental \\ Training, Curitiba, PR, Brazil
}

Correspondence: Karla de Faria Vasconcelos, Av. Limeira, 901, 13414903, Piracicaba, SP, Brazil. Tel: +5519-8294-6677. Fax: +55-19-34210144. e-mail:karlafav@hotmail.com
X-ray microtomography (microCT) is a nondestructive technique used to assess bone morphometry. For an accurate analysis, it is necessary to segment the bone tissue from the background images, avoiding under- or overestimation of the real bone volume. Thus, segmentation methods for microCT can influence the accuracy of bone morphometry analysis. The purpose of this study was to compare two different image segmentation methods available on microCT software (subjective and objective) regarding to the human bone morphometric analysis. Sixteen samples containing a fixation screws covered by $0.5-1 \mathrm{~mm}$ of bone were scanned using the SkyScan 1173 scanner. Three examiners segmented the microCT images subjectively and recorded the threshold values. Subsequently, an objective segmentation was also done. The 3D analysis was performed for both images using the values previously determined in CTAn software. Five bone morphometric parameters were calculated (BV/TV, Tb.Th, Tb.N, Tb.Sp, Conn. Den) and used as dependent variables. ANOVA showed no significant differences between the methods concerning BV/TV ( $p=0.424)$, Tb.N $(p=0.672)$, Tb.Th $(p=0.183)$, Tb.Sp $(p=0.973)$ and Conn. Den $(p=0.204)$. Intra- and interobserver agreement ranged from satisfactory to excellent (0.55-1 and 0.546-0.991, respectively). Therefore, results obtained with subjective threshorlding were similar to those obtained with objective segmentation. Since objective segmentation does not have human input and it is a truly objective method, it should be the first choice in microCT studies that concern homogeneity and high resolution human bone sample.
Key Words: x-ray microtomography, threshold limit values, histomorfometry, bone.

\section{Introduction}

$\mathrm{X}$-ray microtomography (microCT) is a nondestructive technique used to assess bone morphometry. It is a practical and high-resolution tool for measuring trabecular and cortical bone. Several studies have shown the utility of microCT images in quantifying bone tissue (1-3). For an accurate analysis it is paramount to separate the bone tissue from the background images, avoiding under-or overestimation of the real bone volume. Threshold values for segmentation are often selected visually/subjectively, either by analyzing the CT image's histogram or by forcing the resulting binary data set to a volume similar to that of the original bone sample.

Thus, image segmentation methods for microCT can influence the accuracy of bone morphometric investigation (4). Generally, a human operator performs the image segmentation relying solely on one's skills and visual acuity, i.e., subjective segmentation. Alternatively, objective segmentation approaches have been proposed to improve image analysis (2). The most widely used segmentation technique is the global threshold. It is based on histogram analysis and, after a Hounsfield unit value is chosen, all voxels above that value are marked as bone and the remaining voxels are marked as non-bone (4).

The present study aimed to compare the most used objective segmentation technique, the global segmentation or Otsu method, with the subjective method, evaluating if visual acuity could affect the results of morphometric analyses of human bone samples.

\section{Material and Methods}

Bone samples used in this study were obtained from eight patients (five women and three men, mean age 50 years), all suffering from either total or partial maxillary edentulism needing bone grafting before receiving implant-supported oral rehabilitation. All participants voluntarily signed an informed consent after the Research Ethics' Committee of the University of Ponta Grossa, Brazil approved without restrictions (protocol \#14558/11).

One surgeon proficient in bone grafting and implant surgery performed all surgical procedures. First, to assess bone remodeling and to confirm graft integration, conebeam computed tomography (CBCT) scans (Galileos ${ }^{\circledR}$ unit, Sirona Dental Systems, Bensheim) were requested for all patients six months after bone grafting. Afterward, upon the reentry surgery for implant placement, 16 graft fixation screws were removed with a $4.1 \mathrm{~mm}$ diameter trephine drill. The samples consisting of screws with 0.5-to 1-mmthick bone coverage removed from the trephine drill by mechanical "push out" and retained within the 10\% neutral 
buffered formalin solution.

MicroCT data were acquired with a SkyScan 1173 microCT device (Bruker, Kontich, Belgium, output 130kV, electric current $60 \mu \mathrm{A}$, voxel $6 \mu \mathrm{m}, 0.25 \mathrm{~mm}$-thick copper
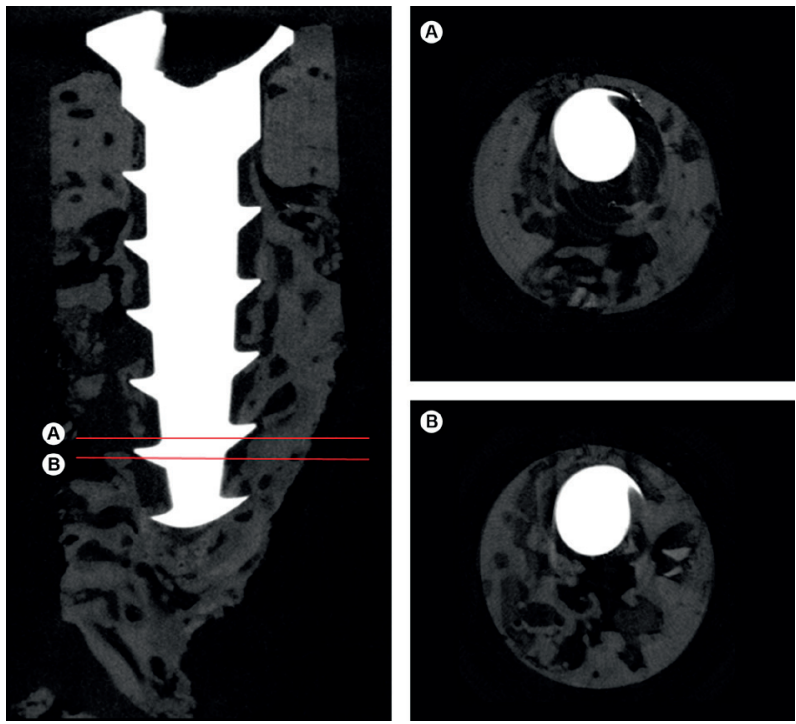

Figure 1. Image showing the interval selection of native bone around the fixation screw. filter, $360^{\circ}$ rotation, rotation step 0.2 , scanning time 60 minutes). Image reconstruction was performed using NRecon software (version 1.6.6.0, Bruker, Kontich, Belgium) and image analysis was performed with CTAnalyzer (Bruker, Kontich, Belgium). During the image reconstruction step, the ring artifact correction was set at 4 and the beam hardening correction at $30 \%$. After exclusion of the fixation screws from the total image, the morphometric parameters were evaluated. To analyze the bone microarchitecture around fixation screws, a volume of interest were selected from each sample totaling ten slices from the native bone area (Fig. 1).

The morphometric parameters selected for the analysis of bone microarchitecture are described in Table 1. All the parameters were named according to Parfitt's system (6) and obtained by means of subjective and objective methods. Firstly, three experienced examiners segmented the images visually/subjectively, and recorded the threshold values (maximum and minimum) for each sample. These threshold values were used to perform the analysis of morphometric parameters in subjective method.

Subsequently, the objective segmentation was done using the "Automatic Threshold" tool available on CTAnalyzer, which is based on the Otsu method (5). After segmentation of the image (Fig. 2), the software itself
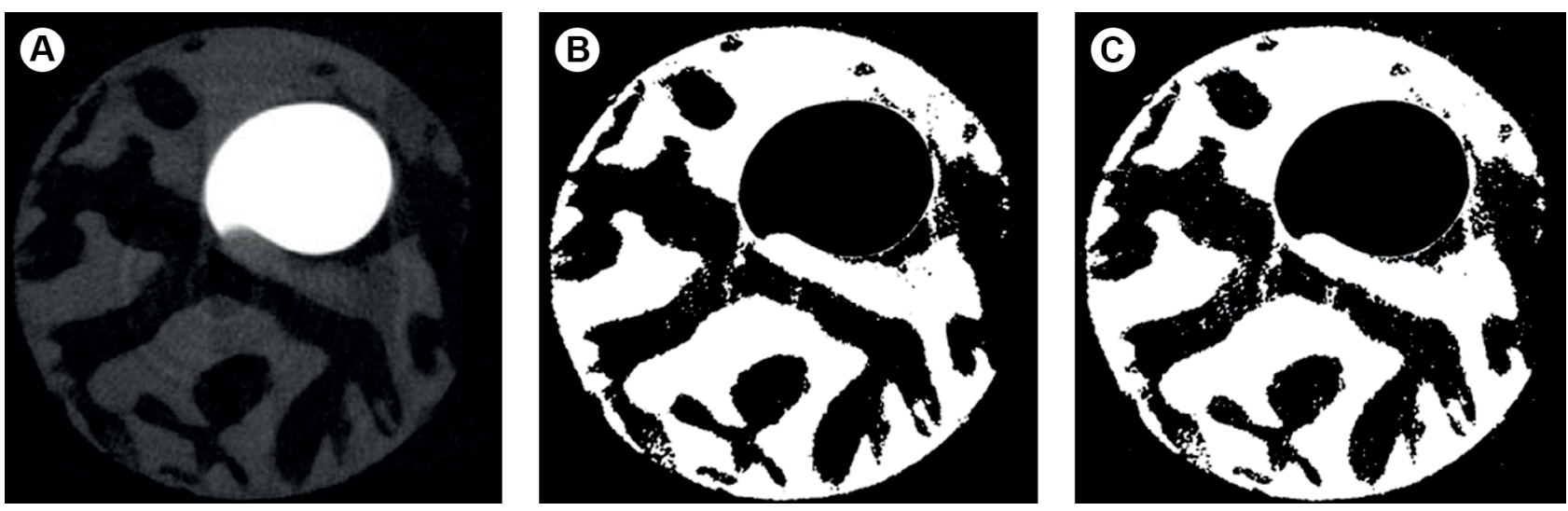

Figure 2. A: Original image in grayscale. Binary image obtained by visual segmentation (B) and automatic segmentation (C).

Table 1. Definition and description of trabecular bone microarchitecture according to Parfitt et al. 1987

\begin{tabular}{|c|c|c|c|}
\hline Abbreviations & Variable & Description & Unit \\
\hline $\mathrm{BV} / \mathrm{TV}$ & Bone volume fraction & Ratio of the segmented bone volume to the total volume of the region of interest & $\%$ \\
\hline Tb.Th & Trabecular thickness & Mean thickness of trabeculae, assessed using direct 3D methods & $\mathrm{mm}$ \\
\hline Tb.N & Trabecular number & Measure of the average number of trabeculae per unit length & $1 / \mathrm{mm}$ \\
\hline Tb.Sp & Trabecular separation & Mean distance between trabeculae assessed using direct 3D methods & $\mathrm{mm}$ \\
\hline Conn.Den & Connectivity density & A measure of the degree of connectivity of trabeculae normalized by TV & $1 / \mathrm{mm}^{3}$ \\
\hline
\end{tabular}


performed the analysis of morphometric parameters in objective method. After 30 days, all the subjective analyzes were repeated for assessing the intraexaminer agreement.

The values obtained with both methods of segmentation were used to compare the methods' agreement applying One-way ANOVA. Intraclass Correlation Coeficient (ICC) was used to assess intra- and interobserver agreement for the subjective method and the intraobserver agreement for the objective method. All statistical tests were performed in the GraphPad Prism 6.0 software (GraphPad Software, La Jolla, CA, USA), considering $\alpha=0.05$.

\section{Results}

Intra- and interobserver agreement ranged from satisfactory to excellent as showed in Table 2.

When the subjective and objective segmentation methods were compared concerning the morphometric parameters, no significant differences were observed: BV/TV $(p=0.424)$, Tb.Th $(p=0.138)$, Tb.N $(p=0.672)$, Tb.Sp $(p=0.973)$ and Conn.Den $(p=0.204)$.

\section{Discussion}

Threshold determination for segmented image is a difficult and nonconsensual aspect in the bone morphometric analysis. At the moment, several segmentation methods available on different software programs are used to subtract bone from the background using distinct computational approaches. In this study, the processing software used was CTAnalyzer, the native software of microCT device which allows the examiner to choose between the subjective or objective segmentation.

The subjective segmentation is based on the histogram of the image. It is the most widely used bone segmentation technique, called "global threshold" in which a Hounsfield unit values is chosen and voxels above this value are marked as bone. The objective method (Otsu method) is used to automatically perform clustering-based image thresholding or, the reduction of a gray level image to a binary image.

Table 2. ICC values for the observer agreement related to the morphometric bone parameters analyzed in the two methods

\begin{tabular}{|c|c|c|c|}
\hline \multirow{2}{*}{$\begin{array}{l}\text { Morphometric } \\
\text { bone } \\
\text { parameter }\end{array}$} & \multicolumn{2}{|c|}{$\begin{array}{l}\text { Visual } \\
\text { method }\end{array}$} & \multirow{2}{*}{$\begin{array}{c}\begin{array}{c}\text { Automatic } \\
\text { method }\end{array} \\
\text { Intraobserver }\end{array}$} \\
\hline & Intraobserver & Interobserver & \\
\hline $\mathrm{BV} / \mathrm{TV}$ & $0.895-0.997$ & $0.838-0.976$ & 1.0 \\
\hline Tb.Th & $0.635-1.0$ & $0.532-0.788$ & 1.0 \\
\hline Tb.N & $0.925-0.996$ & $0.894-0.973$ & 1.0 \\
\hline Tb.Sp & $0.868-0.996$ & $0.91-0.991$ & 1.0 \\
\hline Conn.Den & $0.558-0.964$ & $0.632-0.927$ & 1.0 \\
\hline
\end{tabular}

The algorithm assumes that the image contains two classes of pixels following bi-modal histogram. It then calculates the optimum threshold separating the two classes so that their combined spread is minimal, or equivalently, so that their inter-class variance is maximal (4).

Some authors suggest that the subjective threshold should be used when two contrasting materials have markedly different densities $(7,8)$. Others have suggested an adaptive threshold which implies the creation of a unique threshold for each image based on its histogram (9). Such inconstancy may be disadvantageous, since threshold determination becomes even more subjective and less reproducible. Faced on the doubts regarding to the most accurate method for the human bone analysis, the present study proposed to compare two methods.

According to our results, no significant differences were observed between the subjective (global threshold) and objective method (Otsu method) for the morphometric bone parameters selected. Similar results were found when two subjective methods global and local where compared with histological analysis (4). Their results showed that both segmentation methods tested produced near exact representations of the bone structures when analyzing high-resolution scans of homogenous structures (4). However, the sample was composed by animal bones and the threshold values for subjective method were set in an objective way instead of the subjective choice tested in the present study.

In contrast, a previous study performed with wistar's vertebrae ( $\mathrm{L} 3$ and $\mathrm{L} 4$ ) comparing 4 objective segmentation methods with a subjective segmentation, showed similar results only for BV/TV evaluation, while the others trabecular parameters were different (2). Undoubtedly, the difference between the last and our results could be attributed due to strong difference in the sample.

Our lowest values for intra- and interexaminer agreement were inferior to that found by a previous study (1). The authors tested three objective segmentation methods in which the values for threshold were set in an objective way. The use of a subjective way in the subjective method could explain our lower values that were, however, considered at least satisfactory. In additionally, is important to highlight also that the objective method had perfect agreement that means excellent reproducibility.

The success of a threshorlding algorithm depends strongly on image quality, thus the amount of noise should be reduced and the contrast enhanced (2). In our study, to improve the image quality the ring artifact was corrected at 4 , the beam hardening had $30 \%$ of correction and the images were acquired with $6 \mu \mathrm{m}$ of voxel size (high-resolution). Highlighting the impact of image quality on segmentation step, another study showed that 
when analyzing high-resolution scans $(18 \mu \mathrm{m})$ of bone samples the global threshold methods perform similarly to another automated method tested called "local threshold". However, when scan resolution is relatively low (35-53 $\mu \mathrm{m})$, the objective method tested outperforms the global methods (4).

When analyzing high-resolution scans of a homogeneous bone sample as used in the present study, a subjective thresholding performed similar to the objective thresholding, with the latter being preferable due to the absence of human input.

\section{Resumo}

A microtomografia computadorizada (microTC) é uma modalidade de imagem não destrutiva utilizada para avaliar a morfometria óssea. Para análise acurada, faz-se necessário segmentar o tecido ósseo do fundo (background) da imagem, evitando assim, sub ou sobre estimação do volume ósseo real. Desta forma, fica evidente que os métodos de segmentação em análise de microTC podem influenciar a precisão dos cálculos da morfometria óssea. A realização do presente estudo teve como objetivo comparar o desempenho de dois diferentes métodos de segmentação de imagem de microTC, subjetivo e objetivo, através da avaliação dos resultados das análises morfométricas obtidas de ossos humanos. Dezesseis amostras contendo parafusos de fixação cobertos por 0,5- $1 \mathrm{~mm}$ de osso humano foram escaneados usando o microtomógrafo SkyScan 1173. Três examinadores realizaram a segmentação das imagens de forma subjetiva (visualmente) obtendo seus respectivos valores de threshold. Em seguida, a segmentação objetiva (automática) foi realizada. As análises tridimensionais foram obtidas utilizando os valores determinados por ambos os métodos no software CTAn. Cinco parâmetros morfométricos do osso foram calculados (BV / TV, Tb.Th, Tb.N, Tb.Sp, Conn. Den) e usados como variáveis dependentes. 0 teste ANOVA não mostrou diferenças estatisticamente significantes entre os métodos comparados: BV / TV ( $p=0,424)$, Tb.N ( $p=0,672)$, Tb.Th $(p=0,183)$, Tb.Sp ( $p=0$ 973) e Conn. den $(p=0,204)$. A concordância intra e interobservardores variou entre satisfatória e excelente (0,55-1 e 0,546-0,991, respectivamente). Portanto, os resultados obtidos com a segmentação subjetiva foram semelhantes aos obtidos com a automática. Entretanto, a segmentação automática dispensa intervenção humana, sendo um método verdadeiramente objetivo e deve ser a primeira escolha em estudos microTC que objetivam avaliar a morfometria óssea humana.

\section{References}

1. Chang PC, Liang K, Lim JC, Chung MC, Chien LY. A comparison of the thresholding strategies of micro-CT for periodontal bone loss: a pilot study. Dentomaxillofac Radiol 2013;42:66925194.

2. Gómez W, Sales E, Lopes RT, Pereira WC. A comparative study of automatic thresholding approaches for 3D x-ray microtomography of trabecular bone. Med Phys 2013;40:091903.

3. Chappard D, Retailleau-Gaborit N, Legrand E, Baslé MF, Audran M. Comparison insight bone measurements by histomorphometry and microCT. J Bone Miner Res 2005;20:1177-1184.

4. Waarsing JH, Day JS, Weinans H. An improved segmentation method for in vivo microCT imaging. J Bone Miner Res 2004;19:1640-50.

5. Otsu N. A threshold selection method from gray-level histograms". IEEE Trans Syst Man Cybern 1979;:62-66.

6. Parfitt AM, Drezner MK, Glorieux FH, Kanis JA, Malluche H, Meunier, $\mathrm{PJ}$, et al. Bone histomorphometry: standardization of nomenclature, symbols, and units. Report of the ASBMR histomorphometry nomenclature committee. J Bone Miner Res 1987;2:595-610.

7. Butz F, Ogawa T, Chang TL, Nishimura I. Three- Dimensional Bone Implant Integration Profiling Using Micro-Computed Tomography. Int.
J. Oral Maxillofac Implants 2006;21:687-695

8. Chopra PM, Johnson M, Nagy TR, Lemons JE. Clinical Device-Related Article Micro-Computed Tomographic Analysis of Bone Healing Subsequent to Graft Placement. Biomed Mater Res Part B: Appl Biomater 88B:611-618, 2009.

9. Schouten C, Meijer GJ, Van den Beucken JJP, Spauwen PHM, Jasen JA. The quantitative assessment of peri-implant bone responses using histomorphometry and micro-computed tomography. Biomaterials 2009;30:4539-4549.
Received August 10, 2017

Accepted November 13, 2017 